\title{
How to Incorporate Urban Complexity, Diversity and Intelligence into Smart Cities Initiatives
}

\author{
José-Miguel Fernández-Güell $^{\left({ }^{(}\right)}$, Silvia Guzmán-Araña, Marta Collado-Lara, \\ and Victoria Fernández-Añez
}

Departamento de Urbanística y Ordenación del Territorio, Universidad Politécnica de Madrid, Avenida Juan de Herrera 2, 28040 Madrid, Spain

josemiguel.fernandez@upm.es

\begin{abstract}
Under the term "Smart City", numerous technology-based initiatives are emerging to help cities face contemporary challenges while the concept itself is evolving towards a more holistic approach. Nevertheless, the capability of smart initiatives to provide an integrated vision of our cities is still very limited. Eventually, many of these initiatives fail to understand the complexity, diversity and intelligence that characterize contemporary cities. The purpose of this paper is to display an urban functional system, capable of interpreting the city in a more holistic way and of facilitating effective involvement of local stakeholders in the planning process of SCs initiatives.
\end{abstract}

Keywords: Smart City · Urban complexity $\cdot$ Urban diversity $\cdot$ Urban intelligence

\section{Introduction}

Besides the growing debate that Smart Cities (SC) initiatives are stirring up among their advocates and critics, the seemingly unapproachable complexity and intricate diversity of contemporary cities are hindering conceptual and technical progress in this kind of initiatives. Recent academic contributions recognize the need for developing more integrated and holistic approaches to SCs [1, 2]. In fact, the SC concept is evolving from the simple inclusion of technology in the city to the development of solutions to urban challenges in an interconnected and synergic manner; however, little real progress can be observed in this direction [3, 4].

Therefore, this paper proposes a novel approach that displays the systemic functioning of cities so that SC initiatives can be better assessed not only by technologists and urban planners, but also by a wide range of local stakeholders with no profound expertise in either technology or urban planning. In our view, the use of functional systems provides useful insights about how contemporary cities operate and evolve, and it facilitates the involvement of local stakeholders in the planning process of SCs. 


\section{Characteristics of Contemporary Cities}

Complexity, diversity and intelligence are three key attributes that characterize most contemporary cities $[5,6]$. A close look at those three characteristics may provide a clearer understanding of cities' nature to professionals not directly involved in city sciences.

The first common feature to all large and medium size cities is the high level of complexity of operational processes that take place within the city limits and on its hinterland. Indeed, it is widely accepted that cities are one of the greatest examples of complex systems because they generate an intricate and dynamic network of societal, economic, environmental and political relationships $[7,8]$. That is why complexity has been a recurrent handicap for urban planners because it makes difficult urban analysis and policy making.

The second feature inherent to any big and medium size city is diversity. This important, but elusive feature is generated by the heterogeneity of local agents who intervene in the socioeconomic activities of a city $[9,10]$. In brief, diversity is an important asset of cities as far as the different interests of urban stakeholders are harmonized in benefit of the whole community.

The third attribute of contemporary cities is intelligence. For some authors, urban intelligence means maximizing all the possible connections within the city to improve its operations [11], while for others, the term intelligent city is closely related to the concept of Smart City because it applies a wide range of technological devices [12]. In this paper, we understand the term intelligence as the capability of urban stakeholders to use effectively and efficiently new technologies for managing city operations and for making well informed policy decisions.

Confronted with these challenges, many cities have found in SCs initiatives a strategic option to pull out from present and future problems by heavily investing in technology-oriented solutions. Nevertheless, SCs are presently subject to a heated debate about its advantages and disadvantages. Advocates express the potential of SCs to solve urban challenges $[13,14]$, while there is growing group of critical voices who warn about their potential threats $[12,15,16]$. Despite their pros and cons, SCs could provide reasonable answers about how to approach urban complexity, diversity and intelligence.

\section{How to Approach Urban Complexity}

One way to deal with the complexity of contemporary urban territories is to conceptualize the city as an evolving functional ecosystem. Based on several contributions made in the field of systems theory [17-19], a general system may be defined as a large number of elements which interact among themselves and with the context in which they operate. More specifically, complex systems are characterized by being emergent since they have the ability to generate a new collective behavior through self-organization.

A city may be regarded as a complex ecosystem of connected elements or parts with common purposes, in which human activities, linked by communications, interact as the system evolves dynamically within a given socioeconomic and 
physical context [20,21]. In other words, a city is built from multiple singular initiatives taken through time by a great number of players who are tightly interconnected among themselves. In this ecosystem, any spatial or structural alteration in one of its elements can modify the other parts of the system. Cities, understood as complex systems, are adaptive as they evolve and are not readily predictable because they do not necessarily act in a deterministic fashion.

Compared to other functional systems, cities have some distinctive features that should be taken into consideration [5,22]. The change process in the city is not sequential (one thing directly affecting another), but rather simultaneous (many things happening at the same time). The city is a functional system with a heavy inertia, so there are limits to a city's ability to accelerate or slow down the pace of change. Cities are immersed in a space configured by infrastructures and natural features, all of which influences its functional dynamics. Finally, such a complex system is constantly reacting to external changes, so cities strive to adapt or dominate them, otherwise, they decline.

For the purpose of explaining the complex functioning of a contemporary city, a conceptual model has been developed recently [23] in which the urban ecosystem is synthesized and visualized as a set of different interrelated subsystems (see Fig. 1).

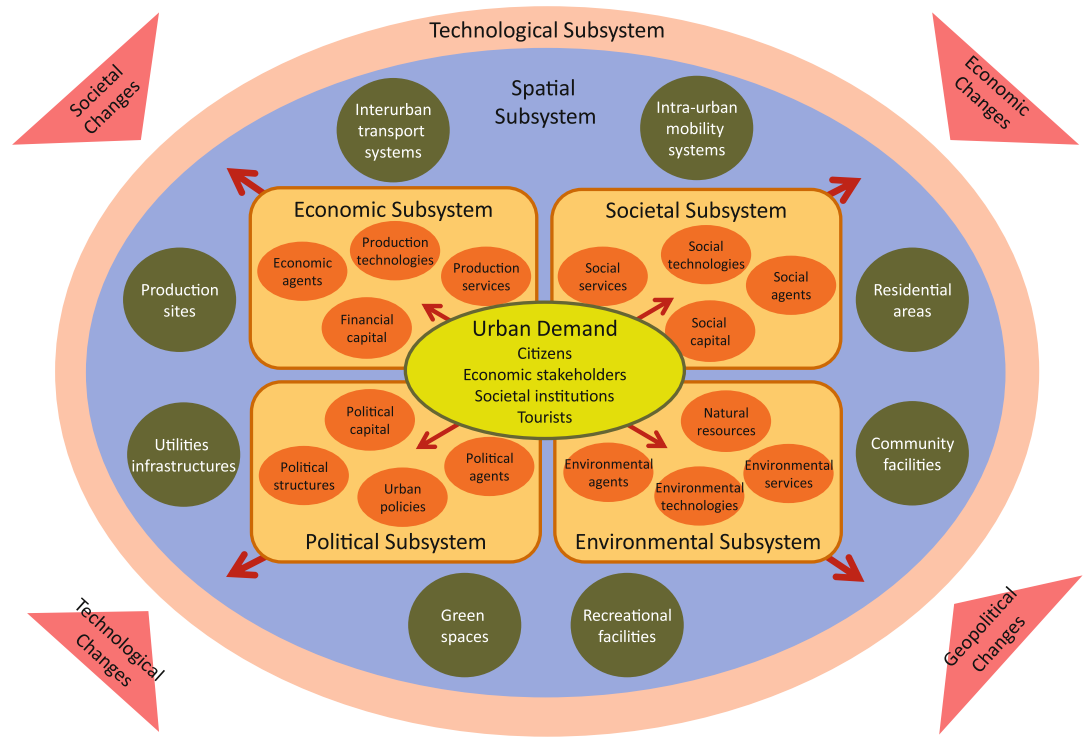

Fig. 1. City's functional system

First of all, urban demand (composed of citizens, economic agents, societal institutions and visitors) is placed in the center of the model. All of them pose a number of requirements on resources, services and infrastructures provided by the urban subsystems so that they can live and work in a city under good conditions. Secondly, acting as suppliers, the city's societal, economic, environmental and political subsystems strive to interpret and satisfy requirements from the different demand segments. Every subsystem is described by its resource capital, operating agents, services provided and 
technology used. Thirdly, those four subsystems request specific physical conditions to the spatial subsystem to operate properly. Thus, the spatial subsystem, regulated by urban planning, is responsible for providing basic infrastructures, transport systems and a wide range of community facilities and housing units. Fourthly, all the previous functional subsystems and demand segments are serviced by a technological subsystem made up of multiple platforms, which ideally should be of transversal nature, though they usually operate for a single sector. Finally, the overall urban system is subject to external change factors, such as demographic transformations, economic cycles, technological innovations or environmental impacts, which affect its functional balance. Indeed, in reality this flow does not happen in such a linear sequence since there are plenty of feedbacks among urban subsystems.

Though it can be perceived as reductionist, this systemic conceptualization of the city has a clear advantage: it displays a simplified, intelligible abstraction of the inherent complexity of our urban reality, which is easily understood by technicians, local stakeholders and citizens. It also analyzes the diverse relationships between urban components as well as it exposes the dominant or dependent positions of both stakeholders and functional subsystems. Thus, the systemic approach strives to reach a better understanding of the urbanization process as well as to establish a common ground for reconciling technologists and urban planners.

\section{How to Approach Urban Diversity}

This paper proposes an approach to urban diversity which is based on the different functionalities performed by cities and on the disparity of local agents. From the functional point of view, cities differ among them because of their geographical location, their spatial pattern, their economic vocation and their socio-demographic structure. Obviously, the bigger and more complex the city is, the most diverse will be.

One way to gain a better understanding of urban diversity is by segmenting and analyzing different city typologies according to the functions performed [24, 25]. In this paper, we use a simple, but didactic segmentation matrix made up of two sets of variables: ranking categories and key functions (see Fig. 2). In that matrix, a qualitative evaluation of the importance of each function is made for every urban typology that may be encountered in the Spanish and European context.

A brief description of the five urban typologies is given as follows:

- Global City. Its influence overpasses national borders. It is characterized by a high level of connectivity, strong technological capacity, wide offering of advanced and financial services, and relevant cultural projection. Multinational corporations are the major urban stakeholders. One of its main challenges is urban governance.

- National Metropolis. It extends its area of influence all over the national state and is strongly linked to other national capitals. They are usually strong decision and administrative centers just as well as important knowledge and transport centers. Some of them are also important industrial centers and tourism destinations. One of their main challenges is to reach a sustainable urban mobility. 


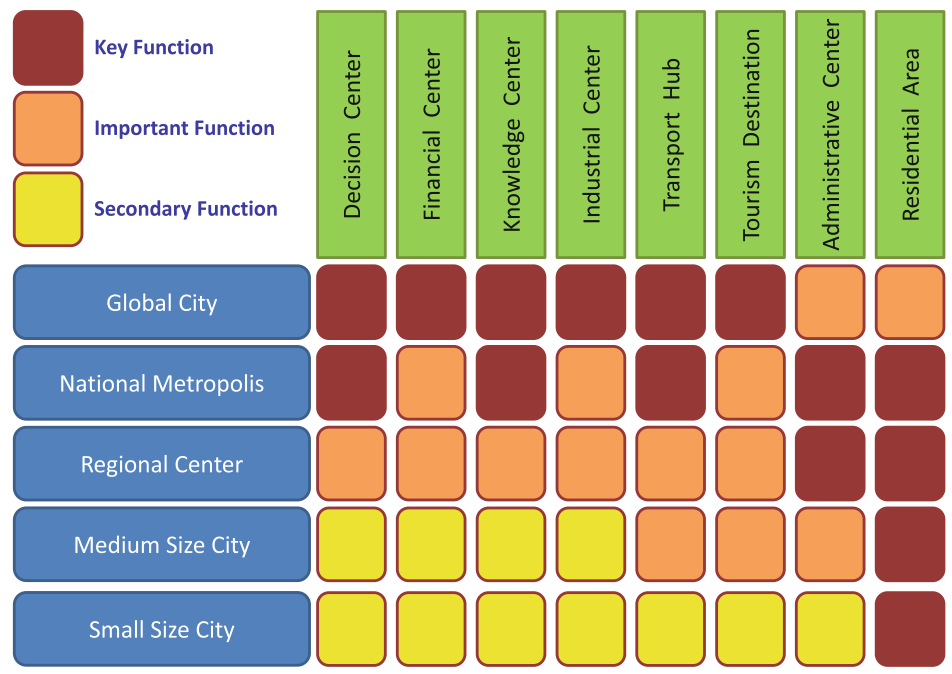

Fig. 2. Segmentation matrix of urban typologies

- Regional Center. Its influence is circumscribed to the regional scale and it serves as a link between national metropolis and intermediate cities. Regional centers tend to be a stronghold of administrative services and they also perform a wide array of urban functions. They are well connected at the national level.

- Intermediate City. It's a key element in structuring urban systems because they play the role of interlinking rural areas with large metropolis as well as balancing territorial development. Because of their limited size, most intermediate cities only specialize in few urban functions. Decisions are taken by local stakeholders.

- Small City. Its influence is usually limited to county borders. Small cities operate as transport centers at the sub-regional level and their economic base is dominated by primary sector activities. Though there are exceptions, in general terms small cities hardly have any specialized functions.

Obviously, this evaluation will vary from country to country, and from continent to continent, when taking into consideration climatic and socio-cultural differences. Nevertheless, this simple segmentation approach may provide plenty of clues for differentiating cities when planning and implementing Smart Cities initiatives. Moreover, intelligence could be considered as an additional transversal variable for further enrichment of the segmentation exercise.

\section{How to Approach Urban Intelligence}

Nowadays, Smart Cities are still a growing phenomenon which is conceptually ambiguous, so there are many "labels" or categories attempting to define the concept [26]. Some of this labels draw attention towards technological aspects [27], while others turn 
into business models [28], level of implantation [29], or maturity of operational processes [30].

Taking into account those contributions, in a recent article we discussed three basic models of Smart Cities with different levels of evolution [31]:

- Sectoral model. It corresponds to the first SCs initiatives which were oriented to satisfy specific vital urban functions, like improving energy efficiency or diminishing $\mathrm{CO}_{2}$ emissions. Some authors refer to this model as ad-hoc projects or technological silos. It is governed by a top-down approach.

- Multi-sectoral model. It constitutes a qualitative improvement of the prior model. Its main purpose is to cluster different sectoral SCs initiatives in order to foster collaboration and synergies among various urban stakeholders. A common language is developed and barriers to adoption are identified. Sustainable funding models and governance issues become a focus.

- Integrated model. It represents the future direction towards which SCs initiatives should be geared. It is an open model which is supported by a citywide technological platform, capable of managing diverse city demands such as environmental sustainability, social inclusiveness, economic competitiveness and citizen participation. It is governed by a mix of top-down and bottom-up approach. In brief, this model constitutes an integrated system of systems and continuous improvements.

According to the integrated model of Smart Cities, urban intelligence is understood as a growing level of connection and integration of services to improve management and decision-making in urban contexts as well as an important tool to empower urban

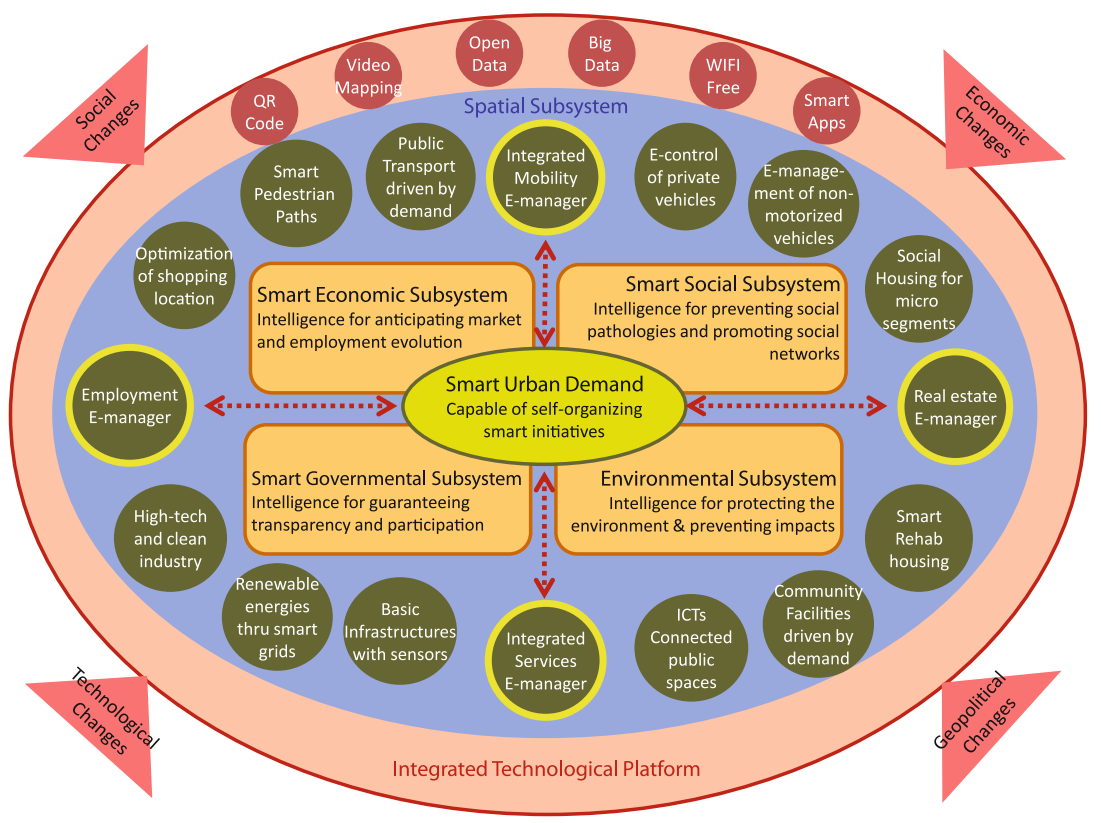

Fig. 3. Integrated model for Smart Cities initiatives 
demand for getting involved in the development of their cities (see Fig. 3). Consequently, all smart devices will be integrated in a transversal platform which will provide smart services to all urban subsystems.

In this context, intelligence becomes a critical part of large and complex city subsystems, which deliver a wide range of products and services requested by a growing smart demand. Therefore, the degree of interoperability or connectivity among urban subsystems will be a key indicator of smart city maturity.

\section{Implementing the Concepts into a Mass Tourism Destination}

As stated before, not all contemporary cities are the same. This paper has opted for displaying just one city typology in order to show the potential of the proposed holistic approach. The selected typology has been a mass tourism destination analyzed in a previous foresight study [32]. Mass tourism destinations are well represented in Spain by cities such as Benidorm, Marbella or Salou.

If we were to plan a future mass tourism destination using the proposed systemic approach, a number of guidelines would be given as follows (see Fig. 4):

Urban Demand: It will be made up of visitors very heterogeneous, demanding and well-informed. City residents will be strongly involved in planning the destination.

Economic Subsystem: It will be driven by innovative tourist business models, adapted to the requests of incoming visitors. Tourism clusters will be developed including several destinations. Tourism services will improve their technological level. Local consumption behavior will be influenced by external demand patterns.

Social Subsystem: The social fabric of the city will be constantly threatened by the large volume of visitors. Destinations will have to manage seasonal immigration flows of low-skilled workers. Social services will have to be adapted to seasonal needs of visitors and workers.

Environmental Subsystem: Mass tourism destinations will have to enhance the value of natural and landscape ecosystems. Tourists' seasonality will be managed to minimize environmental impacts. Attention will be paid to prevent natural hazards.

Political Subsystem: Local governments will implement integrated strategic planning to guide their tourism model. Collaborative planning processes will be based upon citizens' consensus. Tourism demand will be assessed on real time.

Spatial Subsystem: There will be excellent transport connections with tourists' home markets. Within destinations, non-motorized transportation modes will be dominant. Destination's public spaces will be connected to external natural spaces. Tourism facilities will be widely diversified and highly specialized.

Technological Subsystem: Mass tourism destinations will become test-beds for urban technological innovations. New technologies will be tested and applied to urban infrastructures, tourist facilities, transport and public spaces. During holiday periods, tourists will be relaxed and willing to try and enjoy urban innovations. 


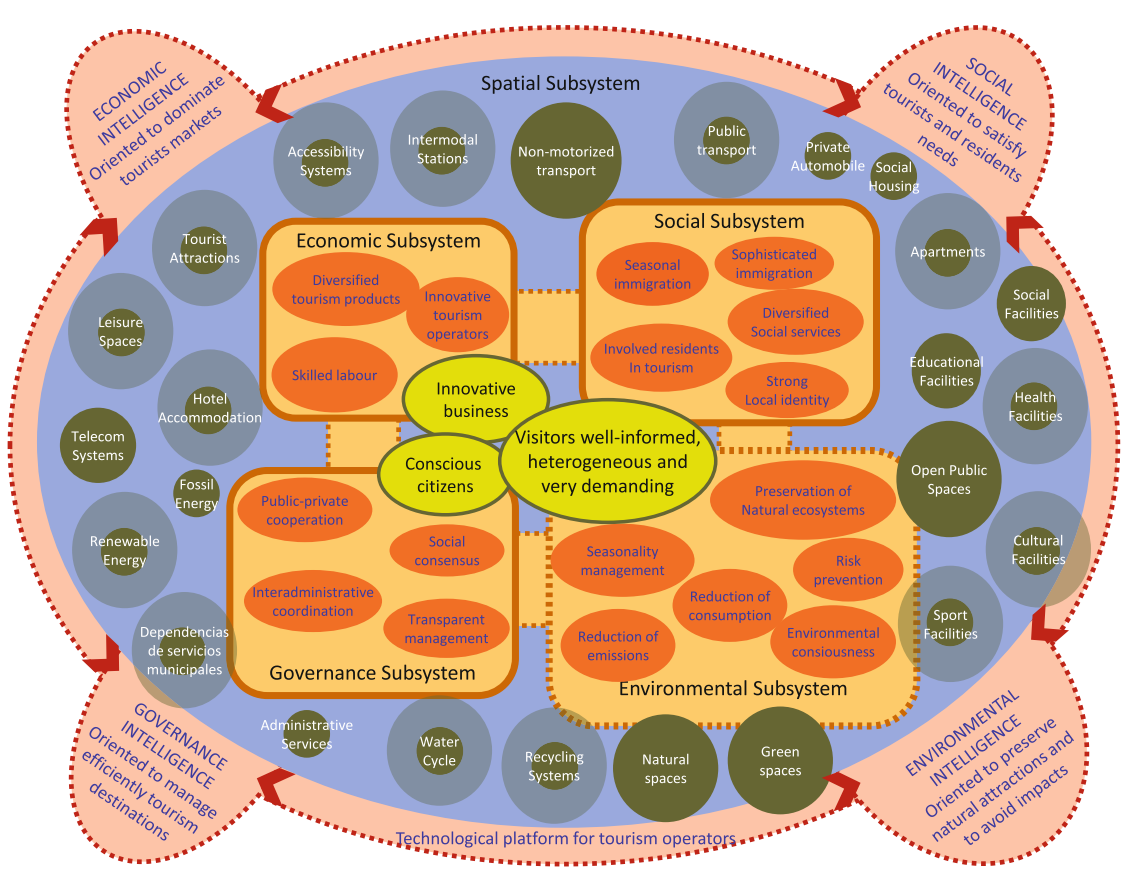

Fig. 4. Functional system of a future mass tourism destination

Some additional interpretations are needed to fully understand Fig. 4. First of all, urban demand is composed of various segments - citizens, business and visitors-with significant differences; however, they share a common interest, the development of the destination under strict sustainability criteria. Secondly, the economic, social, environmental and governance subsystems are well-linked among themselves so as to give timely and effective response to urban demand's requirements. Additionally, the environmental subsystem plays a key role. Thirdly, the spatial subsystem is made up of diverse elements, some of them displaying two concentric circles that show the changing seasonal demand for urban services. Fourthly, besides developing sectoral smart initiatives to solve ad-hoc needs, a citywide technological platform is needed to provide common intelligence to tourism operators, visitors and residents.

\section{Conclusions}

This paper has raised the issue of employing a systemic approach in the development of Smart City initiatives so as to deal with the attributes of complexity, diversity and intelligence, inherent to most contemporary cities.

A set of conclusions related to the systemic approach can be drawn from our paper. Understanding the city as a functional system will allow for an integrated and iconic representation of urban complexity which will be intelligible to most stakeholders. This approach will provide information about how particular subsystems deal with contextual 
issues and how they interact among themselves and develop over time. Increased knowledge about subsystems will improve their operational effectiveness by incorporating technology or other technical resources. Just as well, a systemic approach will facilitate the identification of urban stakeholders, their role and power relations within the community. Finally, under this approach, technology will appear in Smart Cities not like the dominant player, but as a set of tools that will improve malfunctions and will support, in an integrated fashion, the operations of the whole functional system in order to maximize efficiency.

In brief, the employment of a systemic approach will certainly reinforce urban analyses and will provide solid grounds for development strategies, especially when dealing with SCs initiatives. This approach will take into consideration the three key features of contemporary cities -complexity, diversity and intelligence-and will allow for the integration of the Smart City elements.

\section{References}

1. Perboli, G., De Marco, A., Perfetti, F., Marone, M.: A new taxonomy of smart city projects. Transp. Res. Procedia 3, 470-478 (2014)

2. Chourabi, H., Nam, T., Walker, S., Gil-García, J., Mellouli, S., Nahon, K., Pardo, T.A., Scholl, H.: Understanding Smart Cities: an integrative framework. In: Proceedings of 45th Hawaii International International Conference on Systems Science, HICSS-45, 2012, Maui, 4-7 January 2012

3. Mattoni, B., Gugliermetti, F., Bisegna, F.: A multilevel method to assess and design the renovation and integration of Smart Cities. Sustain. Cities Soc. 15, 105-119 (2015)

4. Lombardi, P., Giordano, S., Farouh, H., Yousef, W.: Modelling the smart city performance. Innov. Eur. J. Soc. Sci. Res. 25(2), 137-149 (2012)

5. Fernández Güiell, J.M.: Planificación estratégica de ciudades: nuevos instrumentos y procesos. Editorial Reverté, Barcelona (2006)

6. Camagni, R.: Incertidumbre, capital social y desarrollo local: enseñanzas para una gobernabilidad sostenible del territorio. Inv. Regionales 2, 31-57 (2003)

7. Portugali, J., Meyer, H., Stolk, E., Tan, E.: Complexity Theories of Cities Have Come of Age: An Overview with Implications to Urban Planning and Design. Springer, New York (2012)

8. Allen, P.M.: Cities and regions as evolutionary complex systems. Geogr. Syst. 4, 103-130 (1997)

9. Innes, J., Booher, D.: Consensus building and complex adaptive systems: a framework for evaluating collaborative planning. J. Am. Plan. Assoc. 65(4), 412-423 (1999)

10. Jacobs, J.: The Death and Life of Great American Cities. Random House, New York (1961)

11. Borja, J.: Counterpoint: intelligent cities and innovative cities. Pap. E-J. Knowl. Soc. 5 (2007)

12. Hollands, R.: Will the real smart city stand up? Intelligent, progressive, or entrepreneurial? City 12(3), 302-320 (2008)

13. Cisco: Smart + Connected Communities platform offers solutions in fields such as transportation, learning, safety and security, sports and entertainment, utilities, real estate, health and government (2013)

14. IBM: A Vision of Smarter Cities: How Cities Can Lead the Way into a Prosperous and Sustainable Future. IBM Institute for Business Value, New York (2009)

15. Greenfield, A.: Against the Smart City. Do Projects, New York (2013) 
16. Townsend, A.: Smart Cities: Big Data, Civic Hackers and the Quest for New Utopia. W. W. Norton \& Co., New York (2013)

17. Kauffman, S.: At Home in the Universe: The Search for the Laws of Self-organization and Complexity. Oxford University Press, New York (1995)

18. Forrester, J.W.: Urban Dynamics. MIT Press, Cambridge (1969)

19. Bertalanffy, L.: General Systems Theory: Foundations, Development and Applications. Braziller, New York (1968)

20. McLoughlin, J.B.: Urban and Regional Planning: A Systems Approach. Praeger, New York (1969)

21. Berry, B.J.: Cities as systems within systems of cities. Pap. Reg. Sci. 13(1), 147-163 (1964)

22. Batty, M.: Cities and Complexity: Understanding Cities with Cellular Automata, AgentBased Models, and Fractals. The MIT Press, Cambridge (2005)

23. Fernández Güell, J.M., Collado, M., Guzmán-Araña, S., Fernández-Añez, V.: Incorporating a systemic and foresight approach into smart city initiatives: the case of Spanish cities. J. Urban Technol. (2016, in press)

24. ESPON: ESPON Project 1.4.3 Study on Urban Functions. Final report. Luxembourg: ESPON, March 2007

25. Ministerio de Hacienda y Administraciones Públicas: Estudio sobre tipologías de ciudades españolas, sus necesidades y propuestas de intervención en el tramo de desarrollo urbano sostenible de la programación FEDER 2014-2020. Documento de discusión. Ministerio de Hacienda, Madrid (2014)

26. Caragliu, A., Del Bo, C., Nijkamp, P.: Smart Cities in Europe. J. Urban Technol. 18(2), 6582 (2011)

27. Anthopoulos, L.G., Vakali, A.: Urban planning and Smart Cities: interrelations and reciprocities. In: Álvarez, F. (ed.) FIA 2012. LNCS, vol. 7281, pp. 178-189. Springer, Heidelberg (2012)

28. Alcatel-Lucent: Getting smart about Smart Cities: Understanding the Market Opportunity in the Cities of Tomorrow (2012). http://www2.alcatel-lucent.com/knowledgecenter/publicfiles

29. European Parliament: Mapping Smart Cities in the EU. European Parliament, Directorate General for Internal Policies, Brussels (2014)

30. IDC Government Insights: Smart City Maturity Model Assessment and Action Path to Maturity. IDC (2013)

31. Fernández Güell, J.M.: Ciudades Inteligentes: La mitificación de las nuevas tecnologías como respuesta a los retos de las ciudades contemporáneas. Economía Industrial 395, 17-28 (2015)

32. Fernández Güell, J.M., Collado, M.: Ciudades y ciudadanos en 2033: La transformación urbana de España. PricewaterhouseCoopers, Madrid (2014) 